\title{
The emergence of a clinical skills laboratory and its impact on clinical learning: Undergraduate nursing students' perspective in Limpopo Province, South Africa
}

T M Mothiba, PhD; M A Bopape, MCur; M O Mbombi, BNurs, MCur

Department of Nursing Science, Faculty of Health Sciences, University of Limpopo, Polokwane, South Africa

Corresponding author: M O Mbombi (masenyani.mbombi@ul.ac.za)

\begin{abstract}
Background. Skills laboratory training is used as a teaching strategy to assist nursing students in developing clinical skills. This educational intervention assists nursing students to develop expertise in clinical skills to ensure the safe care of patients. Since the establishment of a new skills laboratory, the Department of Nursing Science, University of Limpopo, South Africa has not evaluated the impact of the laboratory on the clinical learning of nursing students.

Objective. To explore and describe the impact of clinical skills laboratory sessions on undergraduate students in the department.

Methods. Qualitative, descriptive research explored the impact of skills laboratory sessions on undergraduate students. Purposive sampling was used to select participants for the study. Unstructured one-on-one interview sessions were conducted and 12 students were interviewed until data saturation was reached. Thematic content was used for data analysis.

Results. Three themes emerged: the impact of skills laboratory sessions on undergraduate nursing students; the existing benefits of skills laboratory learning sessions; and the importance v. insignificance of laboratory skills lecturers in clinical teaching.

Conclusion. The study revealed that the clinical skills laboratory has a positive, diverse impact on the clinical learning of nursing students. The sessions should be integrated into the curriculum, as they aid in translating theory into practice. Nursing institutions must have a clinical skills laboratory, as they prepare student nurses for learning in a clinical area.
\end{abstract}

Afr J Health Professions Educ 2020;12(4):197-200. https://doi.org/10.7196/AJHPE.2020.v12i4.1375

Skills laboratory training for nurses is an educational intervention that assists nursing students to become experts in performing clinical skills in a clinical context - it enhances their critical thinking when they provide patient care. Clinical laboratory sessions or simulations are conceptualised as a concentrated, individualised effort to improve the performance of a specific skill. ${ }^{[1]}$ Simulation is the reproduction approach of the essential features of a real-life situation and provides students with a learning opportunity regarding clinical and decision-making skills. ${ }^{[2]}$ However, the approach can be categorised as low-fidelity and high-fidelity simulations. ${ }^{[3]}$ Although nurse educators strive to mirror real situations in their skills laboratories using low-fidelity simulation, they often find that nursing students do not have the imaginative attitude necessary to visualise a dummy model as a real patient. Consequently, students frequently experience difficulty in making the transition from skills laboratory learning to real-patient situations in the clinical area. To facilitate this transition, nursing education institutions now use computerised simulation of high-fidelity medical simulations to facilitate clinical learning under the correct conditions, i.e. simulation-based nursing education. ${ }^{[4]}$

Notably, first-level students in all healthcare professions, including nursing, do not have training for handling patients before they start their university programmes. Therefore, clinical laboratory sessions are a suitable way to teach nursing students how to deal with real-life situations. ${ }^{[5]}$ Imran et al. ${ }^{[6]}$ maintain that it is important for students to acquire clinical skills in the skills laboratory, thus making such sessions the best option to assist health professional students to acquire clinical skills before being exposed to real-life settings. ${ }^{[6]}$ These sessions serve to improve clinical acumen and understanding, as well as to enhance the competency of their clinical skills in healthcare settings. Skills laboratory sessions also assist students to be efficient and effective when they are placed in hospital settings, as they can provide quality care to patients, based on the orientation acquired from the sessions. ${ }^{[5]}$ However, students' effectiveness in the given sessions depends on the role played by clinical lecturers.

The duties of clinical skills laboratory lecturers include planning and organising of teaching sessions, designing a learning programme and evaluating programmes to ascertain that the objectives have been met. Clinical skills laboratory lecturers are also expected to develop study materials, including study guides for skills training, to demonstrate clinical skills to students and to assess students regarding these skills, to measure their performance and to keep records as required. ${ }^{[7-9]}$ Löfmark et al. ${ }^{[10]}$ point out that students gained greater independence through clinical learning. Nursing education institutions have to design and implement clinical learning activities that provide students with opportunities to develop their practical skills and, at the same time, to incorporate patient safety principles. ${ }^{[1,12]}$

The clinical skills laboratory of the Department of Nursing Science, University of Limpopo, South Africa (SA) was established in 2010 to provide a conducive learning area for undergraduate nursing students, using demonstrations, simulations and role modelling. Furthermore, the skills laboratory provides voluntary practice sessions across all 
modules of the nursing programme - general nursing science, community nursing science, psychiatric nursing science and midwifery. For example, simulation lessons for nursing students might include insertion of an intravenous line or indwelling urinary catheter on a manikin or a demonstration of a vaginal delivery of a newborn. Furthermore, the effective simulations of all modules are achieved by dividing nursing students into groups of $5-6$, which are spread across the 10 cubicles of the skills laboratory and closely monitored by 2 nurse educators. The skills laboratory gained its momentum for effective clinical skills learning when the department purchased low-fidelity manikins in 2014. Since its establishment, the department has not evaluated the impact of the new skills laboratory on clinical learning among nursing students, while the department continues to use low-fidelity simulations for clinical demonstrations. Viewed from this perspective, the study was undertaken to explore and describe the impact of clinical skills laboratory sessions on undergraduate students in the Department of Nursing Science at the University of Limpopo.

\section{Methods}

Qualitative, descriptive research was used, as this approach examines human experience from the viewpoint of research participants. Qualitative research enabled the authors to interpret and improve their understanding of the impact of skills laboratory sessions on undergraduate students, as the latter gave descriptions of the questions that the authors asked through the exploratory design. ${ }^{[13,14]}$

\section{Population and sampling}

The study was conducted among students registered for the Bachelor of Nursing Science degree with the Department of Nursing Science at the University of Limpopo for the academic year 2017. Purposive sampling was used, based on the judgement of the researchers, to select participants who would represent the student population for the interview sessions. ${ }^{[13]}$ Authors employed purposive sampling to select third- and fourth-level nursing students with good attendance in the skills laboratory. These students were selected because of their clinical exposure level, i.e. whether they were exposed to clinical learning with/without a skills lab in the Department of Nursing Science.

\section{Data collection}

Unstructured one-on-one interview sessions were conducted with 12 students. During these sessions, the main question asked was: 'Can you kindly describe the impacts of skills laboratory sessions that are conducted for you as a student nurse?' Field notes were written and a voice recorder was used to capture all interview sessions..$^{[14,15]}$

\section{Data analysis}

Tesch's open-code qualitative data technique was applied for data analysis, following the steps outlined by Creswell. ${ }^{[16]}$ The data were organised, transcribed verbatim and coded. Categories, themes and sub-themes were generated.

\section{Measures to ensure trustworthiness}

Trustworthiness was ensured by adhering to credibility, confirmability, dependability and transferability. These measures confirm the value of the study and substantiate the researchers' honesty, truthfulness and loyalty to the participants during the research process. Credibility was ensured by interviewing the students and recording all the interview sessions until data saturation. Confirmability was ensured by submission of transcribed data to the independent coder for analysis, and a discussion session was set for the researchers and the independent coder to reach an agreement on codes that were found independently. Dependability was ensured by the writing of field notes and the use of a voice recorder to capture all interview sessions. Transferability was established by describing the research methods followed throughout the study. ${ }^{[17]}$

\section{Ethical approval}

Ethical approval was obtained from the University of Limpopo Turfloop Research Ethics Committee (ref. no. TREC/186/2016). Permission to conduct the study was obtained from the Department of Nursing Science, Faculty of Health Sciences, University of Limpopo. Informed consent was obtained from all participants before the interview sessions. Participants were made aware of their right to autonomy, confidentiality, anonymity and privacy. Data will be kept in a password-encrypted computer document for a period of 5 years.

\section{Results and discussion}

The findings of the study are summarised in Table 1. The themes and subthemes reflect the impact of skills laboratory sessions on undergraduate nursing students of the University of Limpopo.

\section{Theme 1: Description of diverse learning opportunities and the skills laboratory}

The nursing students reported that the skills laboratory provides diverse learning opportunities regarding clinically related contents. The students

Table 1. Themes and sub-themes that reflect the impact of skills laboratory sessions on undergraduate nursing students, University of Limpopo, South Africa

\begin{tabular}{ll}
\hline Themes & Sub-themes \\
\hline 1. Description of diverse learning opportunities on the & 1.1 Skills laboratory sessions aid in translating theory into practice \\
skills laboratory & 1.2 Acquisition of knowledge related to medical equipment used in the clinical area \\
& 1.3 A conducive area to learn more about clinical skills \\
& 2.1 Skills laboratory sessions described as an orientation to clinical contents \\
2. Benefits of skills laboratory learning sessions & 2.2 Skills viewed as a way of eliminating fear and anxiety \\
& 3.1 Clinical lecturers viewed as important in clinical teaching \\
3. Description of the clinical lecturers' role in the skills laboratory & 3.2 Dissatisfaction regarding clinical lecturers who provide clinical teaching during \\
& students' rest time
\end{tabular}


had different views on skills laboratory sessions and the facilitators, which are interpreted according to the following three sub-themes.

\section{Sub-theme 1.1: Skills laboratory sessions aid in translating theory into practice}

The findings reveal that during skills laboratory sessions the students can translate theory into practice. This was supported by one of the participants:

'What is being taught in class is sometimes not easy to understand because it is just something that is written in the book, but when we attend skills laboratory sessions we can understand how the theory is being translated into practice.'

Another participant with the same view stated:

'When something is demonstrated practically [it] is easier to understand than having a theory in mind that you cannot be able to apply it anywhere.'

The use of clinical simulation in nursing education provides many opportunities for students to learn and apply the theoretical principles of nursing care in a safe environment. ${ }^{[18]}$

Sub-theme 1.2: Acquisition of knowledge related to medical equipment used in the clinical area

The findings demonstrate that the skills laboratory sessions provide an opportunity for students to acquire knowledge related to the equipment used in the clinical area. The participants clarified as follows:

'The skills laboratory sessions expose us to some of the equipment that is utilised in the hospital area, such as needles, syringes, suturing pack, urinary catheter, bedpan, body mass scale, apparatus for urinalysis, etc.'

A participant stated:

'When we go to the practical area things become easy as we are already familiar with the equipment that is in used in the hospital.'

Simulation offers many advantages to nursing education, e.g. the clinical setting can be realistically simulated, and there is no threat to patient safety, as during simulation the correct equipment is used so that demonstrations of practical skills can be well presented. ${ }^{[19]}$

\section{Sub-theme 1.3: A conducive area to learn more about clinical skills}

The majority of participants indicated that the skills laboratory improves their clinical knowledge, as it provides a conducive area for them to learn about clinical contents. The skills laboratory impacts positively on their learning, because it assists in executing clinical tasks:

'Being taught a skill in the skills laboratory helps me to improve the level of knowledge I have acquired and makes the clinical area a place that I can be able to carry out my duties diligently'.

Another participant indicated that:

'It prepares us because we have done the procedures in the laboratory sessions and so when we go to the practice setting we know what to expect and what to do.'
Findings show that using simulations is perceived to be a valuable method of learning, which should positively impact the clinical effectiveness of nursing students approaching the transition to registered nurses. ${ }^{[18,19]}$

\section{Theme 2: Benefits of skills in laboratory learning sessions}

The findings indicate that skills laboratory sessions have several benefits for students.

\section{Sub-theme 2.1: Skills laboratory sessions described as an orientation to} clinical skills

Skills laboratory sessions are viewed as part of the clinical skills orientation of students to empower them to perform the required skills competently in a clinical setting. This was confirmed by a participant:

'The skills laboratory sessions orientate us to certain skills that are done in the hospital, such as bed making, taking vital signs, suturing, and many other things, and these sessions assist us so that when we arrive in the hospital we perform those skills as expected.'

Another participant maintained:

'The skills laboratory sessions are very helpful because it orientates us to the clinical skills that are being performed at the hospital and prevents us from being completely blank and helpless; it therefore reduces frustration when we are allocated in the hospital wards.'

A participant shared the same view:

'The skill laboratory sessions make us competent because the clinical skills are repeatedly demonstrated and as students we are then assessed on those skills to ensure our competency before applying the skills in real-life situations.'

Simulation has become more integrated into nursing education in the past 20 years. It is fully integrated into the development of clinical skills for student nurses so that they can be competent when practising. The benefits of skills laboratory sessions, such as simulations, have been discussed by other authors, and are a significant process for the clinical learning of students. ${ }^{[19,20]}$

\section{Sub-theme 2.2: Simulated skills viewed as a way of eliminating fear and} anxiety

The attendance of clinical skills laboratory sessions assists students to dispel fear and anxiety when they are required to perform procedures on real patients in nursing care units. One student confirmed:

'Being trained beforehand about the things that we are going to experience during our practical allocation in hospital, eliminates anxiety and makes us be prepared for that particular event or skill in the hospital. The laboratory skills sessions help us overcome fear.'

The findings are congruent with the those of other authors. ${ }^{[2,20-23]}$ For example, Becker et al. ${ }^{[23]}$ indicated that a potential strategy to minimise anxiety and fear in the clinical setting is by preparation of undergraduate nursing students during their laboratory skills training. The students are trained to portray an illness or a scenario while interacting with other students to create a realistic, low-risk learning experience. ${ }^{[21]}$ 


\section{Theme 3: Description of the clinical lecturers' role in the skills laboratory}

The role of clinical lecturers in the clinical skills laboratory is to assist students in mastering such skills. When these students are placed in hospital wards, they will not experience problems or make mistakes while taking care of patients.

\section{Sub-theme 3.1: Clinical lecturers viewed as important in clinical teaching}

Confidence is a necessity that students cannot obtain on their own regarding the competent performing of clinical skills. Students state that clinical lecturers are important initiators of the confidence they desire in their learning. The following excerpts support these results:

'With the demonstration of the skills by clinical laboratory lecturers, we know what to do at the clinical area. It is easier to do clinical skills because they were demonstrated before. Like when you are busy doing it in the clinical areas you will recall what the lectures have said and done.'

A participant outlined the importance of clinical lecturers:

'Every time I do skills in the practical area, I feel confident because I know what to do and for me, this emerged from the fact that the clinical lecturers were there to create this confidence by demonstrating through simulation the skills.'

The findings are congruent with those of other authors. ${ }^{[20,21,24]}$ For example, Porter et al. ${ }^{[2]}$ indicate that self-confidence is a key component of effective clinical performance and is instilled by laboratory lecturers. Confident students are more likely to be effective and competent nurses. Clinical exposure plays an important role in students' skills acquisition so that they can succeed in the clinical area. ${ }^{[20]}$

\section{Sub-theme 3.2: Dissatisfaction regarding clinical lecturers who provide} clinical teaching during students' rest time

Nursing students were unhappy with clinical lecturers who assume the clinical teaching role during students' rest time. One of the participants maintained:

'Skills laboratory sessions consume our time, as sometimes some of them call us during the weekend for clinical lectures. That is our time to catch up with our studies and also to rest for the following week so that we can be effective. Weekends are meant for us to study and rest.'

In contrast, the study conducted by Porter et al. ${ }^{[24]}$ indicates that students are willing and prepared to be placed in the skills laboratory for clinical learning, which results in building the confidence necessary to perform in healthcare settings.

\section{Study limitations}

Some of the participants were uneasy about giving their honest opinion, as the interview sessions were recorded and might have influenced the findings of the study. Also, given the nature of the study, only a small sample was included. There was no triangulation of data. Quantitative research is warranted to examine the impact of clinical skills laboratory sessions on undergraduate nursing students, involving a larger sample and students in other SA universities.

\section{Conclusion}

This study indicates that students received the emergence of the skills laboratory as a positive establishment in the Department of Nursing Science, which enabled them to gain different clinical learning experiences. Clinical skills laboratory sessions should be integrated into the curriculum, as these aid in translating theory into practice. The sessions orientate students regarding clinical skills, eliminate fears of clinical practice, familiarise them with equipment used in clinical practice, and enhance the confidence of learner nurses. Nursing institutions must incorporate clinical skills laboratory sessions because they prepare student nurses for learning in a practical setting.

\section{Declaration. None.}

Acknowledgements. We acknowledge all learner nurses who participated in this study to make it a success. We also acknowledge the efforts of final-year nursing students of the University of Limpopo, who assisted in data collection.

Author contributions. MOM assisted in the initial conceptualisation and the finalisation of the manuscript. TMM assisted in the second draft and refinement of the manuscript. MAB assisted with writing the methodology and finalisation of the manuscript for publication.

Funding. None.

Conflicts of interest. None.

1. Ericsson KA. Deliberate practice and the acquisition and maintenance of expert performance in medicine and related domains. Acad Med 2004;79(10 Suppl):S70-S81. https://doi.org/10.1097/00001888-200410001-00022

2. Kim J, Park J, Shin S. Effectiveness of simulation-based nursing education depending on fidelity: A meta-analysis BMC Med Educ 2016;16:152. https://doi.org/10.1186/s12909-016-0672-7

3. Medley CF. Using simulation technology for undergraduate nursing education. J Nurs Educ 2005;44(1):31-40.

3. Medley CF. Using simulation technology for undergraduate nursing education. J Nurs Educ 2005;44(1):31-40.
4. Ali L, Nizar S, Ghassan A, Khan SA. Impact of clinical skills laboratory on students' learning in preclinical years. J Ayub Med Coll 2011;23(4):114-117.

5. Alnasir FA, Jaradat AA. The effect of training in primary health care centres on medical students' clinical skills. ISRN Fam Med 2013;1:1-5. https://doi.org/10.5402/2013/403181

6. Imran M, Khan A, Aftab T. Effect of preclinical skill lab training on clinical skills of students during clinical years. Pak J Physiol 2016;12(13):30-32.

7. Francis R. Report of the Mid Staffordshire NHS Foundation Trust Public Inquiry. London: The Stationery Office, 2013:11-14.

8. Issenberg BS, McGaghie WC, Petrusa ER, Gordon DL, Scalese RJ. Features and uses of high-fidelity medical simulations that lead to effective learning: A BEME systematic review. Med Tech 2005;27(1):10-28. https://dol org/10.1080/01421590500046924

9. Nåden D, Slettebø A. Students learning in a skills laboratory. Vård i Norden 2009;29(3):18-22. https://doi org/10.1177/010740830902900305

10. Löfmark A, Carlsson M, Wikblad K. Student nurses' perception of independence of supervision during clinical nursing practice. J Clin Nurs 2001;10(1):86-93. https://doi.org/10.1046/j.1365-2702.2001.00445.x

11. Bradshaw A, Merriman C. Nursing competence 10 years on: Fit for practice and purpose yet? J Clin Nurs 2008;17(10):1263-1269. https://doi.org/10.1111/j.1365-2702.2007.02243.x

12. Peddle M. Simulation gaming in nurse education, entertainment, or learning. Nurs Educ Today 2011;31(7):647-649. https://doi.org/10.1016/j.nedt.2010.12.009

3. Brink H, van der Walt C, van Rensburg G. Fundamentals of Research Methodology for Health Care Professionals Cape Town: Juta, 2006.

14. Grove SK, Gray JR, Burns N. Understanding Nursing Research: Building an Evidence-Based Practice. 6th ed. St Louis, MO: Elsevier Saunders, 2015

15. Moule P, Goodman M. Nursing Research. London: SAGE, 2014

16. Creswell JW. Research Design, Qualitative, Quantitative, and Mixed Methods Approach. 3rd ed. Thousand Oaks, CA: SAGE, 2014.

17. Babbie ER, Mouton J. The Practice of Social Research. Cape Town: Oxford University Press, 2001.

18. Bambini D, Washburn J, Perkins R. Outcomes of clinical simulation for novice nursing students: Communication, confidence, clinical judgment. Nurs Educ Perspect 2009;30(2):79-82.

19. Medley CF, Horne C. Using simulation technology for undergraduate nursing education. J Nurs Educ Medley CF, Horne

20. McCaughey CS, Traynor MK. The role of simulation in nurse education. Nurs Educ Today 2010;30(8):827-832 https://doi.org/10.1016/j.nedt.2010.03.005

21. Gaba DM. The future vision of simulation in healthcare. Simulation Health 2004;13(2):126-135. https://doi org/10.1136\%2Fqshc.2004.009878

22. Numminen O, Meretoja R, Isoaho H, Leino-Kilpi H. Professional competence of practicing nurses. J Clin Nurs 2013;22(9/10):1411-1423. https://doi.org/10.1111/j.1365-2702.2012.04334.x

23. Becker K, Rose L, Berg J, Park H, Shatzer J. The teaching effectiveness of standardised patients. J Nurs Educ 2006;45(4):103-111. https://doi.org/10.3928/01484834-20060401-03

24. Porter J, Morphet J, Missen K, Raymond A. Preparation for high-acuity clinical placement: Confidence levels of final-year nursing students. Adv Med Educ Pract 2013;4:83-89. https://doi.org/10.2147\%2FAMEP.S42157 